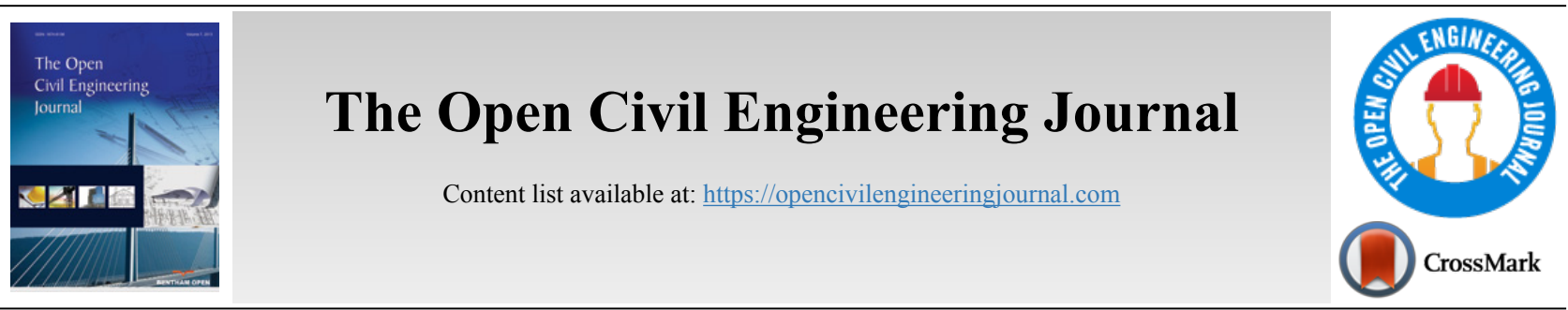

RESEARCH ARTICLE

\title{
Challenges Facing Small-sized Construction Firms in the Gaza Strip
}

\author{
Bassam A. Tayeh $^{1, *}$, Wesam S. Alaloul ${ }^{2}$ and Waleed B. Muhaisen ${ }^{1}$ \\ ${ }^{1}$ Civil Engineering Department, Faculty of Engineering, Islamic University of Gaza, Gaza, Palestine \\ ${ }^{2}$ Department of Civil and Environmental Engineering, Universiti Teknologi PETRONAS, Bandar Seri Iskandar, 32610 Tronoh, Perak, Malaysia
}

\begin{abstract}
:
Background:

The construction industry is the most active tool for societies development and one of the main pillars in the Palestinian economy.

Objective:

The aim of this study is to identify the main internal and external challenges that small-sized construction firms are wrestling in the Gaza Strip. In addition to that, to review briefly small-sized construction firms' characteristics, stages of survival and growth and importance to the economy.

Methods:

At first, all the relevant literature was systematically reviewed. A survey was conducted through a questionnaire to collect the data from 68 contractors. Likert scale data were analyzed to rank the success factors and the barriers using Relative Importance Index (RII).

Results:

The most affecting small-sized construction firms' challenges are: start-up cost, foreign currency fluctuation, access to finance during the execution of work, continuous abruption and unstable prices of construction material, nomination and recruitment policies for the team, the lack of clarity of vision and the difficulty of developing a strategic plan far away, the complexities of dealing with suppliers, and the general economic situation.

Conclusion:

Based on the above challenges, small-sized construction firms should have a protection against unequal competition and a mitigation of financial loads. In addition, group motivational measures, improve the opportunities for the small contractors to survive and grow.
\end{abstract}

Keywords: Challenges, Small sized firms, Construction industry, Gaza strip, SMEs, Relative importance index, Likert scale.

\section{Article History}

Received: February 23, 2019

Revised: May 03, 2019

Accepted: May 16, 2019

\section{INTRODUCTION}

The construction industry has one of the highest failure rates among other industries. It is known of its complexity and tough competitive environment. A significant number of emerging firms in the construction sector fail within the first months of operation and make no remarkable signs of growth or even the ability to survive [1]. The contribution and significance of small and medium-sized enterprises (SMEs) as an important engine of growth are receiving increased attention in both developed and developing countries. These enterprises are often regarded as the "backbone" of the economy, serving as major sources of technological development, new jobs and

* Address correspondence to this author at the Civil Engineering Department, Faculty of Engineering, Islamic University of Gaza, Gaza, Palestine;

Tel: 00972595174717; E-mail: btayeh@iugaza.edu.ps a seedbed for entrepreneurship. They produced $73 \%$ of the sector's total value added and $69 \%$ of its output, in addition to employing $71 \%$ of the total workforce and generating $75 \%$ of the sector's total compensation. Moreover, their remuneration levels were on a par with those of the sector, with their compensation-to-value-added ratio only $1 \%$ higher than the sector as a whole. So the increasing demand on housing and related infrastructure and services led a notable number of investors to enter the field of construction, but due to lack of basic skills and inability to meet demands and then low survival rates, they ultimately fail $[2,3]$.

In the Gaza Strip, small sized construction firms are in critical context due to their high failure rates. A preliminary inexperienced survey is enough to realize that the majority of small firms sustains disturbing conditions and predicts a dark 
future. The effect of this issue does not only concern the owners and investors but it affects the socio-economic development process in general. Internal and external challenges and issues must be discussed through the successive stages of emerging small construction firms' evolutionary line. These stages are: (1) Start-up; (2) Survival and success; and (3) Growth. Despite the small-sized construction firms' importance, they are seldom paid attention to strategic plans by the decision makers [4]. There is a misleading idea when it comes to identifying the challenges facing small-sized construction firms between the financial aspects and the managerial factors. Therefore, the aim of this study is to discuss the challenges facing small-sized construction firms in the Gaza Strip.

\section{LITERATURE REVIEW}

The construction sector is considered as one of the most important economic sectors that affect the Palestinian national economy. Due to the interrelated relations with other economic activities, the construction sector has a vital role because of its contributions in finding housing, public services and infrastructure [5]. The construction market of Gaza Strip has many unique features that potentially can cause delays and additional costs overrun ending in disputes. Small enterprises are considered to be one of the most important elements of development in countries in general, whether economic or social, because of their effective role in dealing with poverty and unemployment. They also play a major role in increasing economic productivity. SMEs are well-known to be one of the main areas of concern to many strategy makers in the effort to speed up the rate of development in low-income countries to achieve the growth objectives [6].

According to Bezuidenhout [7], small business can be defined by means of numerous different lines. Businesses may be classified as "small" in terms of a number of parameters like physical size, sales turnover, the number of employed people and production capacity. There are three key characteristics that should be taken into consideration when defining a small business. First, in terms of economic, a small business should have a relatively small share of its market. Second, a small business management should be its owners themselves and should be free from outside control in their major decisions. And third, it is independent which means that it does not form part of a larger business. The concept of small and medium terms varies from country to country, and even from one region to another within the same country. There is no unanimous definition of Small Construction Firms (SCFs), which are also considered as enterprise or business. Some of the usually used criteria are the number of workers, value of fixed assets, value of trades and size of invested capital as well as the turnover. Nevertheless, the National Board for Small Scale Industries (NBSSI) defined small and medium enterprise as "one which employs not more than twenty-nine persons with plant and machinery value (excluding land, buildings and vehicles) not exceeding the equivalent of US\$100,000" [8]. Small-sized firms are different from other firms by the following characteristic: Direct supervision by the owner of the project, since the management of these projects is carried out by the owner personally. Therefore, the project management and decisions are flexible to ensure the success of the work of the project and a kind of human relations between workers within the project are built. The ease of adapting production according to the needs are taking into account the consumer's satisfaction and the rapid change in the market. In addition, small sized firms have less risk than others $[9,10]$.

Business growth is the increase in the size of a simple or complex economic unit, made with structural changes and possibly of system variables accompanied by economic progress. This concept is inextricably linked with the increase in the size and structural change of the firm [11]. Lewis and Churchill, 1983 delineated five stages of development of a growing business which were; existence, survival, success, take-off, and resource maturity [12].

SMEs development is blocked by several challenges that are related to the regulatory environment, management skills, financial infrastructure, lending capacity and liquidity and the availability of risk-sharing instruments. Aigbavboa and Thwala [13] summarized the main challenges faced by small contractors cash flow, construction management skills, contract documentation, working relationships, facilities and equipment, communication cultural impact, and financial management skills. The aim of this study is to identify the main internal and external challenges that small-sized construction firms are facing at the Gaza Strip. In addition to that, small-sized construction firms' characteristics, stages of survival and growth, source of funding and importance to the economy have been reviewed.

\section{METHODOLOGY}

In this study, a questionnaire survey (a quantitative approach) was used to collect the factual, perceptive, and attitudes of the respondents $[14,15]$. A pilot study for the questionnaire was conducted. The participants were asked to examine the questionnaire and confirm the validity of the questionnaire and its own relevance to the study objectives and give their comments. Generally, they decided that the questionnaire would work to attain the study objectives with comments and important points which have been addressed. The targeted population was the construction companies which have a valid registration in the Palestinian Contractors Union (PCU) in Gaza Strip. In order to decide the sample size of the population, Eqn 1 was used $[16,17]$.

$$
n=n^{\prime} /\left(1+\frac{n^{\prime}}{N}\right)
$$

$n$ ': is the sample size from infinite population, which can be calculated from this formula

$\left[n^{\prime}=S^{2} / V^{2}\right]$ : The definitions of all variable can be defined as the following; $n$ : sample size from finite population; $\mathrm{N}$ : Total population (85 small sized construction firms); V: Standard error of sample population equals 0.05 for the confidence level 95; $\mathrm{S}^{2}$ : Standard error variance of population elements, $\mathrm{S}^{2}=\mathrm{P}(1-\mathrm{P})$; maximum at $\mathrm{P}=0$. 
The sample size can be calculated from the previous equations as follows:

$$
\begin{gathered}
\mathrm{n}^{\prime}=\mathrm{S}^{2} / \mathrm{V}^{2}=(0.5)^{2} /(0.05)^{2}=100 \\
\mathrm{n}=100 /(1+100 / 85)=46 \text { firms }
\end{gathered}
$$

Although the calculated sample size is forty-six, the questionnaire was distributed to seventy-five firms to overcome the risk of not responding from the respondents and to reflect higher reliability. Sixty-eight questionnaires were received with $90 \%$ response rate. Likert scaling was used to measure the responses through questionnaires in a survey research. The respondents were asked to give their perceptions in-group of questions on five-point scale1, to record their disagreement and agreement, which reflects their assessment regarding the factors affecting the bidding process.

The collected raw data were first sorted, edited, coded and then entered into computer software. Two software were used, the Excel sheet and SPSS. The ordinal scale is a rating data, which uses integers in ascending or descending order. The Relative Important Index (RII) was used in the analysis. In addition, Analysis of Variance (ANOVA) tests, frequencies and percentiles were used. The RII method has been widely used in construction research to calculate and formulate attitudes with respect to surveyed variables. Then, the RII was computed using Eqn 2 [18 - 24]:

$$
\mathbf{R I I}=\frac{\sum w}{A N}=\frac{5 n_{5}+4 n_{4}+3 n_{3}+2 n_{2}+1 n_{1}}{5 N}
$$

where $\mathrm{W}$ is load given for every factor by the respondent, between 1 to $5,(\mathrm{n} 1=$ number of respondents for who agreed strangely, $\mathrm{n} 2=$ number of respondents who don't agree, $\mathrm{n} 3=$ number of respondents for neutral, $\mathrm{n} 4=$ number of respondents for agree, $\mathrm{n} 5=$ number of respondents who agreed strangely). $\mathrm{A}$ is the first load (i.e. 5 in the study) and $\mathrm{N}$ is the total number of samples. RII value is between 0 and 1 . The analyzed data was finally presented using descriptive methods for easy interpretation and to enable and make comparison easy.

\section{RESULTS AND DISCUSSION}

Questionnaire results were obtained from 68 questioners,
Section one of the questionnaire discusses the personal information of the respondents of the questionnaire, Section two discusses the basic information of the examined construction firms and Section three discusses the factors related to finance, factors related to material and equipment, factors related to the human resources, factors related to the higher management skills, factors related to communication and work relations and factors related to the business environment all represent the challenges facing the new smallsized construction contracting firms. These sections were designed to achieve the defined objectives of this research and to propose recommendations to improve the criteria of the work to guarantee the success of these firms.

\subsection{Personal Information of the Respondents}

Table 1 shows that $36.8 \%$ from the sample nature of work is "Chairman", 32.4\% "Executive manager", 16.2\% "Project Manager", 8.8\% “Site Engineer”, and 5.9\% “Office Engineer". The majority of the respondents are from high management positions because they are often the owners of the business and they do not need or tend to hire much employees. Table $\mathbf{1}$ further shows that $35.3 \%$ from sample's experience in the company "Less than 5 years", $35.3 \%$ "5 to 10 years", $20.6 \%$ "10 to 15 years", and $8.8 \%$ "More than 15 years".

\subsection{Basic Information of the Examined Firms}

Table 2 shows that $91.2 \%$ of the companies have 1 to 5 number of permanent employees, and only $8.8 \%$ of the companies have 6 to 10 permanent employees. The results are definitely expected; small firms' owners are often the ones who cover all the duties themselves. In addition, Table $\mathbf{2}$ shows that $45.03 \%$ from type of business carried out by the company are "Building construction", 33.11\% "Roads", 9.93\% "Water \& Drainage", 2.65\% "Electro-mechanic", and 9.27\% "Public works and Maintenance". With respect to the average of projects carried out by the companies, the results show that $79.4 \%$ from the average value of projects carried out by the company annually are "Less than $\$ 1$ million", and $20.6 \%$ are "from $\$ 1$ to less than $\$ 2$ million". The results reflect the

\begin{tabular}{|c|c|c|c|c|c|}
\hline Nature of Work of the Respondent & Freq & $\%$ & Number of Years of Work in the Company & Freq & $\%$ \\
\hline Chairman & 25 & 36.8 & Less than 5 years & 24 & 35.3 \\
\hline Executive manager & 22 & 32.4 & 5 to 10 years & 24 & 35.3 \\
\hline Project Manager & 11 & 16.2 & 10 to 15 years & 14 & 20.6 \\
\hline Site Engineer & 6 & 8.8 & More than 15 years & 6 & 8.8 \\
\hline Office Engineer & 4 & 5.9 & & & \\
\hline Total & 68 & 100.0 & Total & 68 & 100.0 \\
\hline
\end{tabular}
difficulty of accessing to work opportunities.

Table 1. Nature of work of the respondents.

Table 2. Basic Information of the Examined Firms.

\begin{tabular}{|c|c|c|c|c|c|c|c|c|}
\hline \multicolumn{2}{|c|}{ No of Permanent Employees } & \multicolumn{5}{|c|}{ Type of Business Carried Out } & \multicolumn{3}{|c|}{ Average Value of Projects Carried Out by the Company Annually } \\
(US \$)
\end{tabular}


(Table 2) contd.....

\begin{tabular}{|c|c|c|c|c|c|c|c|c|}
\hline \multicolumn{3}{|c|}{ No of Permanent Employees } & \multicolumn{3}{|c|}{ Type of Business Carried Out } & \multicolumn{3}{|c|}{$\begin{array}{l}\text { Average Value of Projects Carried Out by the Company Annually } \\
\text { (US \$) }\end{array}$} \\
\hline Employees & Freq & $\%$ & Business & Freq & $\%$ & Project value & Freq & $\%$ \\
\hline 6 to 10 & 6 & 8.8 & Roads & 50 & 33.11 & $1-2$ million & 14 & 20.6 \\
\hline 11 to 15 & 0 & 0.0 & Water \& Drainage & 15 & 9.93 & & & \\
\hline \multirow[t]{2}{*}{ More than 15} & 0 & 0.0 & Electromechanic & 4 & 2.65 & & & \\
\hline & & & Public works and Maintenance & 14 & 9.27 & & & \\
\hline Total & 68 & 100.0 & Total & 151 & 100.00 & Total & 68 & 100.0 \\
\hline
\end{tabular}

Table 3. Challenges groups Relative Importance Index.

\begin{tabular}{|c|c|c|c|c|c|}
\hline Challenges Groups & Mean & Std. Deviation & \%of Relative Importance Index & t-value & Rank \\
\hline Financial challenges & 3.96 & 0.369 & 79.25 & 21.505 & 1 \\
\hline Material and Equipment & 3.96 & 0.549 & 79.12 & 14.355 & 2 \\
\hline Business environment & 3.61 & 0.466 & 72.12 & 10.711 & 3 \\
\hline Human resources & 3.46 & 0.591 & 69.12 & 6.366 & 4 \\
\hline Higher management skills & 3.25 & 0.701 & 65.00 & 2.941 & 5 \\
\hline Communication and work relations & 3.03 & 0.545 & 60.69 & 0.520 & 6 \\
\hline
\end{tabular}

Table 4. The most important challenges for small-sized construction firms.

\begin{tabular}{|c|c|c|c|c|c|c|c|}
\hline No. & Factor & Mean & Std. Deviation & $\%$ of RII & t-value & P-value & Rank \\
\hline \multirow{3}{*}{ Finance Factors } & Start-up cost (Company registration) & 4.53 & 0.610 & 90.59 & 20.671 & 0.000 & 1 \\
\hline & Foreign currency fluctuation & 4.24 & 0.775 & 84.71 & 13.145 & 0.000 & 2 \\
\hline & Access to finance during the execution of work & 4.15 & 0.815 & 82.94 & 11.603 & 0.000 & 3 \\
\hline \multirow{3}{*}{$\begin{array}{l}\text { Material and Equipment } \\
\text { Factors }\end{array}$} & Continuous abruption of construction material & 4.74 & 0.444 & 94.71 & 32.196 & 0.000 & 1 \\
\hline & High and unstable prices of construction material & 4.47 & 0.610 & 89.41 & 19.876 & 0.000 & 2 \\
\hline & Price manipulation and monopoly of construction material & 4.15 & 0.815 & 82.94 & 11.603 & 0.000 & 3 \\
\hline \multirow{3}{*}{ Human Resources Factors } & Nomination and recruitment policies for the team & 3.74 & 0.785 & 74.71 & 7.729 & 0.000 & 1 \\
\hline & Policies to maintain staff stability & 3.65 & 0.877 & 72.94 & 6.084 & 0.000 & 2 \\
\hline & Lack of interest of qualified people to join the work & 3.53 & 1.126 & 70.59 & 3.877 & 0.000 & 3 \\
\hline \multirow{3}{*}{$\begin{array}{l}\text { Management Skills } \\
\quad \text { Factors }\end{array}$} & $\begin{array}{l}\text { The lack of clarity of vision and the difficulty of developing a } \\
\text { strategic plan far away }\end{array}$ & 3.62 & 0.978 & 72.35 & 5.209 & 0.000 & 1 \\
\hline & The need for a permanent marketing system and skills & 3.32 & 0.969 & 66.47 & 2.754 & 0.008 & 2 \\
\hline & The need for professional consultants in the field of construction & 3.29 & 0.899 & 65.88 & 2.699 & 0.009 & 3 \\
\hline \multirow{3}{*}{$\begin{array}{l}\text { Communication and } \\
\text { Work Relations Factors }\end{array}$} & $\begin{array}{l}\text { Involvement of the owner in the details of the execution of the } \\
\text { work }\end{array}$ & 3.59 & 0.738 & 71.76 & 6.575 & 0.000 & 1 \\
\hline & Complexities of dealing with suppliers & 3.44 & 0.817 & 68.82 & 4.451 & 0.000 & 2 \\
\hline & Low turnout rates and difficult customer satisfaction & 3.38 & 0.847 & 67.65 & 3.723 & 0.000 & 3 \\
\hline \multirow{3}{*}{$\begin{array}{l}\text { Business Environment } \\
\text { Factors }\end{array}$} & The general economic situation is unstable & 4.47 & 0.657 & 89.41 & 18.451 & 0.000 & 1 \\
\hline & Competitive nature of construction and contracting & 4.00 & 0.846 & 80.00 & 9.743 & 0.000 & 2 \\
\hline & Corruption in some governmental and private institutions & 3.85 & 0.851 & 77.06 & 8.264 & 0.000 & 3 \\
\hline
\end{tabular}

\subsection{Small Sized Construction Firms Challenges}

This part shows the results of the respondents regarding the challenges faced by the small-sized construction firms which are divided into six groups as follow: Financial challenges, Material and equipment, Human resources, Higher management skills, Communication and work relations, and Business environment. Table 3 illustrates the Mean, Std. Deviation, $t$-value, and the rank of the challenges groups according to RII. Financial challenges are the biggest challenge to the small contractors, RII $79.25 \%$. Material and equipment ranked second with RII of $79.12 \%$, it is undoubted that supplying material to projects is a challenge that is disturbing small contractors because of the close link to the political and security affairs in the Gaza Strip. Finally, the lowest score was for communication and work relations field, RII $60.69 \%$. Despite the importance of the factors of this field and the mandatory need to cover them professionally, it is not striking that the field occupies the last position because respondents would be inattentive towards factors that are related to the personal characteristics of the firm's owners.

\subsection{The Most Important Challenges for Small-sized Construction Firms}

The highest three factors from each group are illustrated in 
Table 4 ranged from highest to lowest according to RII.

Factors related to the Finance Results from Table 4 indicated that the Start-up cost was the highest loading factor with a mean equals " 4.53 ", RII " $90.59 \%$ " and P-value equal 0.000 which is smaller than the level of significance $\alpha=0.05$. The result seems logical and predictable. The founders of new construction firms in Gaza Strip are expected to expend a minimum amount of ten thousand dollars to cover the registration fees at the government departments, the Chamber of Commerce and the Contractors' Union. In addition, they will also bear the expenses of the Law office and Accounting office beside the expenses of opening a bank account and getting a checkbook. All the above, besides the expenses of establishing and furnishing an office according to standards, form a real obstacle to beginner investors. Mafimidiwo [25] indicated that the majority of small contractors obtained their start-up capital from personal savings and this is the reason for the excessive interest in this factor. The second-high factor loaded in this component was (Foreign currency fluctuation) with a mean equals "4.24", RII "84.71\%", and P-value 0.000 , which is smaller than the level of significance $\alpha=0.05$. The majority of the construction projects in Gaza Strip gets funds from international relief societies that depend on non-local currency transactions. Therefore, determining the most appropriate price to establish the value of the foreign currency in local currency to reach the optimum bid price, is a real challenge. Especially as the process of tendering, awarding and execution extends for a long time, which means there is enough margin for a change in the currency exchange rate which is fluctuating in nature.

Factors related to material and equipment (Continuous abruption of construction material) was the highest loading factor with a mean equals "4.74", RII "94.71\%" and P-value equal 0.000 which is smaller than the level of significance $\alpha=$ 0.05 . The logical factor is due to the unilateral control by the Israeli government of the crossings and the entry of materials and personnel into the Gaza Strip, the entry of construction materials for projects has become closely linked to security and political issues. The second-high factor loaded in this component was High and unstable prices of construction material, with a mean equals " 4.47 ", RII " $89.41 \%$ ", and Pvalue 0.000 , which is smaller than the level of significance $\alpha=$ 0.05 . As a result of the restrictions imposed on the entry of construction materials, the prices of building materials are high compared to their prices from the source, or their price in the neighboring regional markets.

Factors related to the human resources (Nomination and recruitment policies for the team) were the highest loading factor with a mean equals "3.74", RII " $74.71 \%$ " and P-value equal 0.000 which is smaller than the level of significance $\alpha=$ 0.05 . It can be concluded that a large number of arising companies are known to be the family businesses or companies based on the partnership of former friends or colleagues, and the policies for the nomination of team members for projects are a serious challenge. The second-high factor loaded in this component was policies to maintain staff stability with a mean equals " 3.65 ", RII " $72.94 \%$ ", and P-value 0.000 , which is smaller than the level of significance $\alpha=0.05$. As the nature of work in small-sized companies depends on the mixing of tasks assigned to employees, unlike the big companies that tend to specialize. It is a constant concern for small-sized companies to develop a policy to maintain the basic staff by seeking to provide continuous work to ensure the minimum coverage of these staff.

Factors related to the management skills (The lack of clarity of vision and the difficulty of developing a strategic plan) were the highest loading factor with a mean equals "3.62", RII " $72.35 \%$ " and P-value equal 0.000 which is smaller than the level of significance $\alpha=0.05$. In the Gaza Strip, the security and political situation are always unpredictable. Therefore, the result here was expected and it also applied to all companies whether large, medium or small-sized. The result is not far from what Mafimidiwo [25] listed in their study of problems faced by small building contractors. In their study, strategic planning was among the ten most influential with forty-five factors. The second-high factor loaded in this component was the need for a permanent marketing system and skills with a mean equals " 3.32 ", RII " $66.47 \%$ ", and P-value 0.000 , which are smaller than the level of significance $\alpha=0.05$. Marketing for a company in contracting is very important. All employees in this field have seen the shift in bid evaluations and to what extent the interest in the technical evaluation of companies has become urgent. What makes it even more urgent for newly emerging companies is that the general culture towards newcomers is always negative because they are unknown. The result matches to what Bouazza et al. [26] concluded in their study of factors affecting the growth of small businesses in Algeria.

Factors related to communication and work relations (Involvement of the owner in the details of the execution of the work) were the highest loading factor with a mean equals "3.59", RII "71.76\%" and P-value equal 0.000 which are smaller than the level of significance $\alpha=0.05$. The role of the owner in the success of the project is undeniable, especially its role in defining the scope of the project and facilitating of payments to the contractor. The result matches to those of Raghavan and Kumar [27] who listed the involvement of the owner as of the third loaded factor. The second-high factor loaded in this component was complexities of dealing with suppliers with a mean equals " 3.44 ", RII " $68.82 \%$ ", and Pvalue 0.000 , which is smaller than the level of significance $\alpha=$ 0.05 . The difficulty is expected to emerge as a result of the difference in business reputation and financial resources between the parties. The supplier may not be interested in dealing with a small-sized company that buys construction materials in small quantities and spaced frequency. The contractor's need to purchase materials pay by installments or delayed payments may force the contractor to comply with the supplier's conditions, including raising the price for deferment of payments. In addition, choosing a supplier that agrees to delay payments may often mean choosing the inappropriate supplier. The result meets with the reference $[25,27]$ and it definitely matches practical facts.

Factors related to the business environment (The general economic situation is unstable) was the highest loading factor with a mean equals " 4.47 ", RII " $89.41 \%$ " and P-value equal 0.000 which is smaller than the level of significance $\alpha=0.05$. 
The economy in Gaza is suffering from the Israeli blockade since 2007. The movement of goods and individuals (businessmen) through the crossings is almost paralyzed. As a result, employment opportunities are not available, the average income is very low and the incentives for urban expansion and the development of infrastructure are virtually non-existent. Therefore, the chances of projects will be less and the general competition will be more severe. The economic blockade for a relatively long time has created a pessimistic and unfavorable atmosphere for investment. Aigbavboa and Thwala [13] also ranked the economic situation as the second loaded factor among all the factors in their local studies. The second-high factor loaded in this component was (Competitive nature of construction and contracting) with a mean equals " 4.00 ", RII " $80.00 \%$ ", and P-value 0.000 , which is smaller than the level of significance $\alpha=0.05$. The competitive environment is one of the incentives to attract investment in open and healthy markets. The problem lies not in the competition itself, but in the unequal competition between small companies and large companies, which have been driven by the lack of opportunities to compete for small projects. The result is common in many similar studies such as Mafimidiwo and Iyagba [25] who ranked competition as the highest loaded factor among all factors. In addition, Aigbavboa and Thwala [13] ranked competition as the third loaded factor while Raghavan and Kumar [27] ranked competition as the fifth loaded factor.

\section{CONCLUSION}

Small firms are active participants in the national economic empowerment, especially in developing countries. In the Gaza Strip, despite their importance, small firms have seldom paid attention to strategic plans and studies. The study was carried out through a questionnaire survey to the small-sized construction firms' representatives. The study found that the most important groups of challenges are as follows: Financial challenges, challenges related to material and equipment, challenges related to human resources, challenges related to higher management skills, challenges related to communication and work relations and finally, challenges related to the general business environment. The most influencing challenges are: start-up cost, foreign currency fluctuation, access to finance, continuous abruption of construction material, high and unstable prices of construction material, nomination and recruitment policies for the team, policies to maintain staff stability, the lack of clarity of vision and the difficulty of developing a strategic plan, the need for a permanent marketing system and skills, involvement of the owner in the details of the execution of the work, complexities of dealing with suppliers, the general economic situation and competitive nature of construction and contracting. Some of the factors are strongly related to the nature of the construction industry, some are related to the characteristics of small-sized firms and some are specific to the general situation of the Gaza strip.

\section{CONSENT FOR PUBLICATION}

Not applicable.

\section{FUNDING}

None.

\section{CONFLICT OF INTEREST}

The authors declare no conflict of interest, financial or otherwise.

\section{ACKNOWLEDGEMENTS}

Declared none.

\section{REFERENCES}

[1] M. Agwu, and A. Emeti, "Issues, challenges and prospects of small and medium scale enterprises (SMEs) in Port-Harcourt City. Nigeria", Eur. J. Sustain. Dev., vol. 3, pp. 101-107, 2014. [http://dx.doi.org/10.14207/ejsd.2014.v3n1p101]

[2] W. Alaloul, M. Liew, and N. Zawawi, "Attributes of coordination process in construction projects. Engineering Challenges for Sustainable Future", Proceedings of the 3rd International Conference on Civil, Offshore and Environmental Engineering (ICCOEE 2016), Malaysia, 2016 pp. 169-172

[http://dx.doi.org/10.1201/b21942-33]

[3] W.S. Alaloul, M.S. Liew, and N. Zawawi, "Coordination process in construction projects management. Engineering Challenges for Sustainable Future", Proceedings of the 3rd International Conference on Civil, Offshore and Environmental Engineering (ICCOEE 2016), Malaysia, 20162016 pp. 149-153 b

[http://dx.doi.org/10.1201/b21942-29]

[4] Kh. El-Hallaq, and B.A. Tayeh, "Strategic planning in construction companies in Gaza strip", J. Eng. Res. Techno., vol. 2, pp. 167-174, 2015 .

[5] B.A. Tayeh, Kh. El-Hallaq, W.S. Alaloul, and A.R. Kuhail, "Factors affecting the success of construction projects in Gaza strip", Open Civ. Eng. J., vol. 12, pp. 301-315, 2018.

[http://dx.doi.org/10.2174/1874149501812010301

[6] K. El-namrouty, "The impact of construction sector on palestinian economy - case study", Americ. Acad. Scholar. Res. J., vol. 4, pp. 1-18, 2012.

[7] S. Bezuidenhout, "Advantages associated with the implementation and integration of environmental management systems in small manufacturing businesses", M.S. Thesis, University of Stellenboschof, Stellenbosch, South Africa, 2003.

[8] F.K. Bondinuba, "Exploring the challenges and barriers in accessing financial facilities by small and medium construction firms in Ghana", Civ. Environ. Res., vol. 2, pp. 25-35, 2012.

[9] O.A. Tayeh, Kh. El-Hallaq, and B.A. Tayeh, "Importance of organizational culture for Gaza strip construction companies", Int. J. Eng. Manage. Res., vol. 8, pp. 35-39, 2018.

[10] O.A. Tayeh, Kh. El-Hallaq, and B.A. Tayeh, "The organizational culture of Gaza strip construction companies", Int. J. Eng. Manage. Res., vol. 8, pp. 40-64, 2018.

[11] D. Louis, and P. Macamo, "Barriers to business growth: A study on small enterprises in Maputo", M.S. Thesis, Umea School of Business, Swede, 2010.

[12] V. Lewis, and N. Churchill, "The five stages of business growth, issue of Harvard Business Review", Available from: https://hbr.org/1983/05/the-five-stages-of-small-business-growth

[13] C. Aigbavboa, and W. Thwala, "Challenges facing black owned small and medium construction companie: A case study of Nelspruit Mbombela Municipality", South Africa", J. Econ. Behav. Stud., vol. 6, pp. 771-778, 2014.

[14] R. Fellows, and A. liu, "Research Methods for Construction, Blackwell Science Ltd.: Oxford, 1997.

[15] G. Israel, "Determining sample size", Institution of Food and Agricultural Science, University of Florida, pp. 11-15, 2003. Available from:

https://www.tarleton.edu/academicassessment/documents/Samplesize. pdf

[16] A. Enshassi, M.A. Faisal, and B.A. Tayeh, "Subcontractor prequalification practices in Palestine", Int. J. Construct. Manage, vol. 10, pp. 45-75, 2010.

[http://dx.doi.org/10.1080/15623599.2010.10773154]

[17] A. Enshassi, F. Arain, and B.A. Tayeh, "Major causes of problems 
between contractors and subcontractors in the Gaza Strip", J. Financ. Manage. Property Construct., vol. 17, pp. 92-112, 2012.

[http://dx.doi.org/10.1108/13664381211211064]

[18] B.A. Tayeh, Kh. Al-Hallaq, and F.A. Sabha, "Effects of faulty design phase on school buildings maintenance in Gaza strip", Americ. J. Civ. Eng. Arch., vol. 4, pp. 199-210, 2016

[http://dx.doi.org/10.12691/ajcea-4-6-2]

[19] M.A. Albhaisi, B.A. Tayeh, and Kh. El-Hallaq, "Variation orders in construction projects in Gaza strip (case study: Qatar projects)", Int. J. Eng. Manage. Res., vol. 6, pp. 262-270, 2016.

[20] B. A. Tayeh, Kh. Al-Hallaq, M. O. Yusuf, and F.A. Sabha, "Effects of construction phase errors on maintenance of school buildings in Gaza strip", Int. J. Manage., Inform. Techno. Eng. (BEST: IJMITE), vol. 5, pp. 21-34, 2017.

[21] K. Mahfuth, A. Loulizi, Kh. Al-Hallaq, and B.A. Tayeh, "Implementation phase safety system for minimising construction project waste", Buildings, vol. 9, pp. 1-21, 2019. [http://dx.doi.org/10.3390/buildings9010025]

[22] K. Mahfuth, A. Loulizi, B.A. Tayeh, and Kh. Al-Hallaq, "Unacceptable forms of work for safety in the construction sector- palestinian national authority", Int. J. Civ. Eng. Techno, vol. 9, pp. 328-341, 2019.

[23] B.A. Tayeh, S. Durdyev, I.O. Abuzuhri, and D. Thurnell, "Contractors' attitudes towards the factors affecting sustainability performance: Evidence from Palestine", Busin. Strat. Devleop, vol. 2, pp. 1-7, 2019. [http://dx.doi.org/10.1002/bsd2.51]

24] B.A. Tayeh, Kh. Al-Hallaq, S.Y. Kim, W.S. Alaloul, and A.H. A Faqawi, "An Examination of the critical success factors and barriers of last planner system implementation in the Gaza Strip construction industry", Open Constr. Build. Technol. J., vol. 12, pp. 389-403, 2018. [http://dx.doi.org/10.2174/1874836801812010389]

[25] B. Mafimidiwo, "Comparative study of problems facing small building contractors in Nigeria and South Africa", J. Emerg. Trends Econ. Manag. Sci., vol. 6, pp. 101-109, 2015.

[26] A.B. Bouazza, D. Ardjouman, and O. Abada, "Establishing the factors affecting the growth of small and medium-sized enterprises in Algeria", Am. Int. J. Soc. Sci., vol. 4, pp. 101-121, 2015.

[27] V. Raghavan, and K. Kumar, "Problems faced by small scale construction contractors in India, Int", Re. J. Eng. Techno., vol. 2, pp. 105-107, 2015.

\section{(C) 2019 Tayeh et al.}

This is an open access article distributed under the terms of the Creative Commons Attribution 4.0 International Public License (CC-BY 4.0), a copy of which is available at: (https://creativecommons.org/licenses/by/4.0/legalcode). This license permits unrestricted use, distribution, and reproduction in any medium, provided the original author and source are credited. 